\title{
The Double or, an Architecture of Estrangement
}

\author{
FRANCESCO MARULLO \\ University of Illinois at Chicago
}

\begin{abstract}
Drawing from Dostoevsky's novel The Double and EI Lissitzky's Prouns, the essay meditates on the estranging effect of the axonometric vision, considered not as a mere technique of representation but as a project of awareness: as a method to dissect reality, to reveal its constituting mechanisms and the way it functions.
\end{abstract}

Dostoevsky's free-indirect-speech and El Lissitzky's reversible drawings transformed axonometry into a machine generating images for understanding rather than seeing, for distancing more than seducing, questioning rather than persuading, analyzing more than illustrating. Deliberately rejecting the tyrannical vanishing point of perspective, the parallel projection is un-appropriable and collective being undefinable within the limits of a single observer, indifferent to either top-down or bottom-up constructions, and rejecting unified notions of audience, gender, standards or any other molar generalization such as "the people."

Within and against an architectural production that rapidly transforms everything into a visual episode, wherein communication often counts more than the message itself, consumption more than production, curation more than creation, circulation more than content, the ubiquitous alienating distance that separates us from our selves, lives, and actions, could be reversed into an instrument for selfconsciousness and collective valorization.

Learning from Dostoevsky and Lissitzky's axonometric visions, the critical process of architectural drawing becomes useful not just to penetrate reality in all its aspects, but also to look at ourselves and at the conditions in which we live critically, to re-appropriate our will to action and reestablish a meaningful relationship with others.

Why do we have a mind if not to get your way? -Fyodor Dostoevsky

A person as no internal sovereign territory, he is wholly and always on the boundary; looking inside himself, he looks into the eyes of another or with the eyes of another. -Mikhail Bakhtin

In 1846 Fyodor Dostoevsky published his second novel, The Double. The story narrates the internal psychological struggle of a government clerk, Yakov Petrovich Golyadkin, who repeatedly encounters somebody with a striking resemblance to himself. Despite being a mental projection, this other Golyadkin provokes tangible effects on the real Golyadkin: fear, envy, angst, suspicion, panic, hesitancy, an increasing sense of inadequacy and an exacerbated self-criticism.

Anticipating some of the characters that would later populate Dostoevsky's underground, Golyadkin's story demonstrates that not only the sleep of reason can conjure monsters, but also its excessive wakefulness can lead to deformation, to use Manfredo Tafuri's words. ${ }^{1}$ The hallucinatory state of duplicity does not stem from a delirious condition of the protagonist but, on the contrary, from a hyperbolic consciousness that progressively impregnates the whole image of the world. The more Golyadkin scrutinizes reality, the less he is able to control his own actions. The more he constructs and dismantles his subjectivity the more he gets cramped into troubles.

Arguably, modernity precisely corresponds with the emergence of such an acute sensibility and intensified autocriticism: the transformation of the self into research, into a process that deflects expectations and defies any external scope beyond its becoming. Modernity is not an efficient adherence to function, but the crude operation of reason aimed at sounding out the deepest regions of the self and what stands beyond them from a clinical point of observation.

The dissecting table of modernity could not be better elucidated than Dostoevsky's opening pages of his Notes from the Underground, speaking through the words of a "sick man": "I swear, gentlemen, that to be too conscious is an illness, a real thorough-going illness (...) But yet I am firmly persuaded that a great deal of consciousness, every sort of consciousness, in fact, is a disease. (...) The more conscious I was of goodness and of all that was 'sublime and beautiful,' the more deeply I sank into my mire and the more ready I was to sink in it altogether. But the chief point was that all this was, as it were, not accidental in me, but as though it were bound to be so. It was as though it were my most normal condition, and not in the least disease or depravity so that at last all desire in me to struggle against this depravity passed. It ended by my almost believing (perhaps actually believing) that this was perhaps my normal condition."

Although The Double is written in the third person, the narrator-author is not omniscient and never wholly detached from the two characters. The narrator is chained to the hero 
and unable to achieve a distance perspective or to provide a general overview of Golyadkin's actions and the events. As Mikhail Bakhtin noted, the geometry of the whole novel is constructed as an interior dialogue of three voices within the limits of a single dismantled soul. Every essential aspect of the story lies at the intersection of these three voices, "at a point where they abruptly, agonizingly interrupt one another."2

The plot proceeds as a polyphonic narration, where the writer is not above the characters but a voice among the many other ones in the story: the chorus of Golyadkin's consciousness. No-one can escape Golyadkin's monologue, and its turbulent flow entirely swallows even the author. The narrator does not have a privileged higher position since the continuous dialogic stream of Golyadkin negates any possibility to frame the whole story within a single comprehensive image: a univocal vanishing point with a measured system of relations.

Bakhtin remarks the absence of "perspective" in this particular use of language: "Employing a term from art criticism, we could say that Dostoevsky had no 'distance perspective' on the hero and the event. (...) Narration in Dostoevsky's later period is brief, dry, and even somewhat abstract (especially in those places where information is provided about earlier events). But this brevity and dryness of narration, results not from a perspective, but on the contrary, from the lack of any perspective. Such deliberate lack of perspective is preordained by Dostoevsky's entire artistic plan, for, as we know, a firm and finalized image of the hero and the event is excluded in advance from that plan."3

Objects, places, people, situations, and emotions are rendered as closer and more objectively than the ones filtered through a single viewing eye of the narrator. Dostoevsky replaces the consistent central position of the observer postulated by the perspectival technique with a polycentric and fragmented narrator, suggesting a sort of "axonometric" structure, wherein all the points have different positions but share a common infinite directionality rather than a converging tendency to a unique point. Whereas perspective reproduces the world as it appears to an observer in a particular position, axonometry preserves the actual measurements of the things represented, without converging or receding lines. Once the observer is removed and displaced to an external position, then the object and its internal mechanisms - or, in Dostoevsky's case, the subject and the interior landscape of the mind - suddenly move to the foreground.

Paraphrasing Massimo Scolari, axonometry refuses a holistic point of view to represent not the object in space but the space of the object itself. ${ }^{4}$ Thus, the novel does not focus on the subject in space but on the very space of interiority although observed from a distance. Adopting such an entirely "inhuman" point of view - an estranged anonymous position obtained through streams of light rather than a converging pyramid of vision - it would be possible to produce an isometric dimension uncorrupted by human perception: an abstract form of reality that represents what we tacitly know rather than what we see. Similarly, to render the subject in its very true form, Dostoevsky detaches the totality of the represented world from the single observer-narrator moving it towards a polyphonic multiplicity of point of views, creating a non-converging projection and eliminating the tyrannical vanishing point of the author.

Whereas perspective admits a controlled composition within a precise proportional net, axonometry allows free punctual extrusions and endless juxtapositions. For Bakhtin, this specific narrative technique through which the writer assumes the language, tones, thoughts, and gestures of the characters, is a typical example of free-indirect-speech: a strategy to displace the encumbering role of the author and inform the story with an impersonal, nomadic, narrating voice. The free-indirect-speech transforms the novel into an automatic architecture: an architecture working on itself, unfolding from its inner logic and mechanisms, able to get rid of everything externally imposed, even of its author.

In Golyadkin's story, all the elements are connected yet independent from each other as in an axonometric parallel projection. The individual as a finite composite entity does not exist as it is an assemblage of parts differently related to each other. The "I" is composed of endless facets of equal value and always caught in the perennial struggle of becoming itself. Golyadkin's monologue operates as a diffracting device not only to penetrate the multiplicity of the human subconscious, but also to understand how this multiplicity resonates in the way men dwell the world and fabricate their subjectivities, rituals, and behaviors.

Before Sigmund Freud, Dostoevsky's Double revealed the unconscious as a vast interiorized territory wherein Golyadkin oscillates between the excessive signification of his visions and dispersive performances, rational control and immanent drives, paranoia, and schizophrenia.

The novel moves along a twofold reversible direction of estrangement: a paranoid tendency (from the Greek pará noos "next or beyond the mind") that surveys, filters, aggregates and inflects information in internal hierarchies and schemes towards an exacerbated center; and a schizophrenic tendency, (literally from skhizo and phren "split mind") which overthrows and dispels the center towards external lines of flights. ${ }^{5}$ While the first projects the self upon the world, fabricating a subjective reality inside-out, the latter introjects the world via the dissolution of the self, generating trajectories outside-in. On one side, all the world is folded and registered within an interiority; on the other, the consciousness breaks apart into endless variations and branches. 


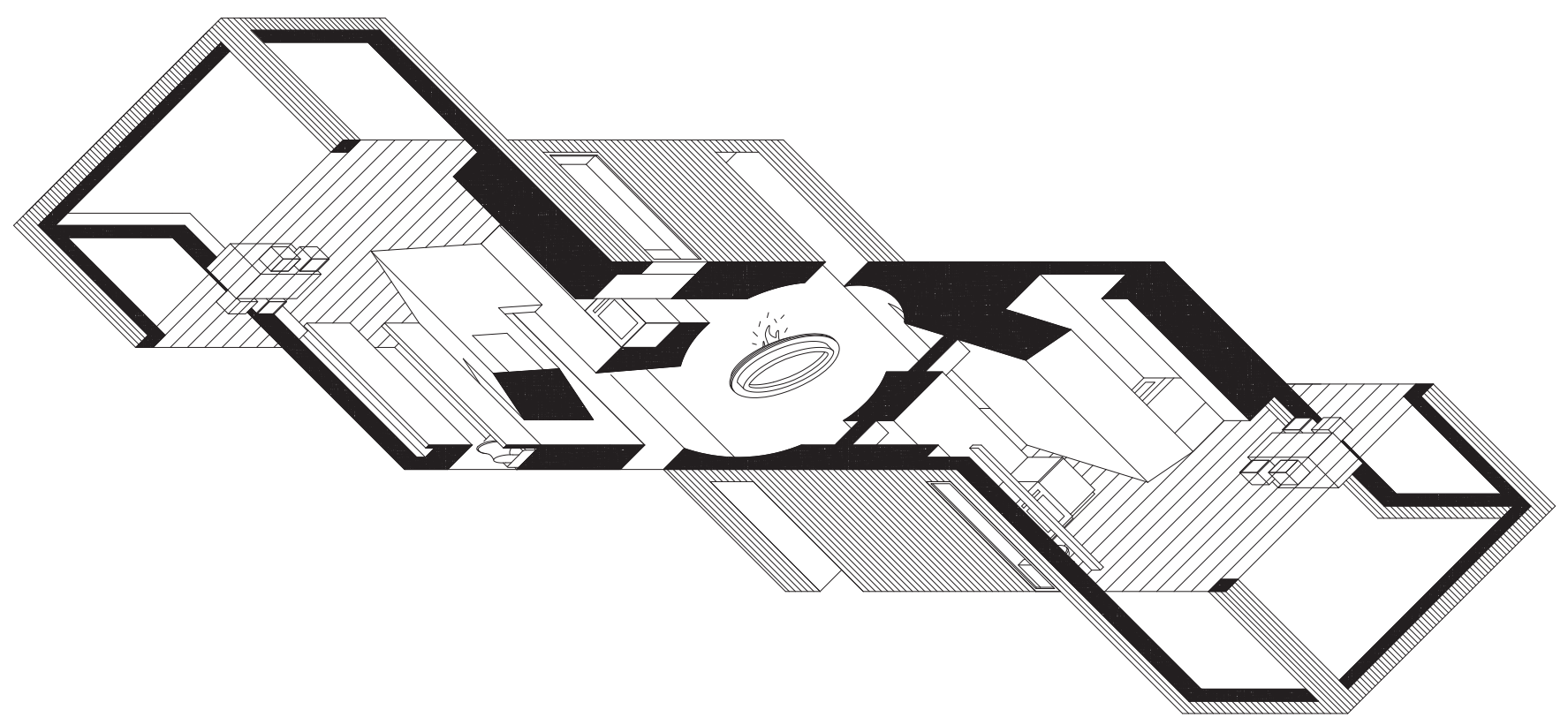

Figure 1. Three Rooms. Stacie Merz (extract from Doppelgänger, An Architecture of Estrangement. A graduate design research studio led by Francesco Marullo, UIC School of Architecture, Spring 2018).

Certain aspects of Dostoevsky's anti-perspectivism could be partly derived from his interest in the long artistic tradition of Russian and Byzantine icons. Featuring multiple vanishing points, incorrect aberrations, lines diverging towards the horizon, abnormal shadows, accentuated use of colors emphasizing distortions, over-detailed object vis-à-vis vague masses, icons praised a polycentric construction of the image to trigger a mental reconstruction of its content beyond the image itself, similarly to the polyphonic anti-perspectival dialogic passages of Dostoevsky's novels.

The alleged illiteracies of the Russian icons were necessary to abandon the static imprisonment and the lack of temporality of the perspectival construction: icons had not to duplicate reality but to penetrate its hidden structures, materials, and meanings profoundly. The deliberate and meticulous transgression of the perspectival rules produced assemblages of autonomous parts, whose formal clarity could have only been read and reorganized in the conscience of the beholder, evoked in the spiritual movement or interior rhythm, as in Golyadkin's monologues.

Russian iconography reverses the Euclidean laws of linear perspective. It rejects an absolute observation point, a univocal horizon, and a coherent convergence, proposing different views of reality at the same time. In this way, the observer does no longer occupy a fixed position in front of the image: eyes are free to wander across the different parts of the composition, establishing associations, recovering memories and generating emotions. The architecture of the image is no longer conceived as a simple translation of reality but a process of abstraction that requires both the active participation and the critical logical detachment of the observer. Real facts are not flat, static, immutable or repetitive, but presuppose concentrations and dilatations, accelerations and slowdowns, unleashing intensities directly related to the sensory organs of the beholders, forces which would be imperceptible within the homogeneity of the perspectival reticulum.

Besides Dostoevsky, many Russian intellectuals used the religious tradition of icons as a reference for their work at the onset of the 20th century. Among others El Lissitzky, whose work moved from the planimetric organization of formal material to the translation of a three-dimensional space onto flat surfaces through a series of stratifications with both expanding or compressing effects typical of the iconographic tradition.

In his 1925 essay $A$. and Pangeometry, Lissitzky constructs a history of perspective as the following acknowledgment of a reversible depth, capable of inscribing the world into a box or project it beyond the pictorial plane. Lissitzky identifies the apex of the visual pyramid as a double point that could be either located in the eye of an observer standing in front of an object or projected towards the horizon and thus positioned behind an object. The pictorial plane suddenly becomes a conceptual threshold - a "zero" point - not just dividing a positive from an infinite negative dimension but also defining a twofold perception moving from and through the image: "Suprematist space may be formed not only forward from a plane but also backward in depth. If we indicate the flat surface of the picture as 0 , we can describe the direction in depth by - (negative), and the forward direction by + (positive), or the other way around. Thus, Suprematism has swept away 


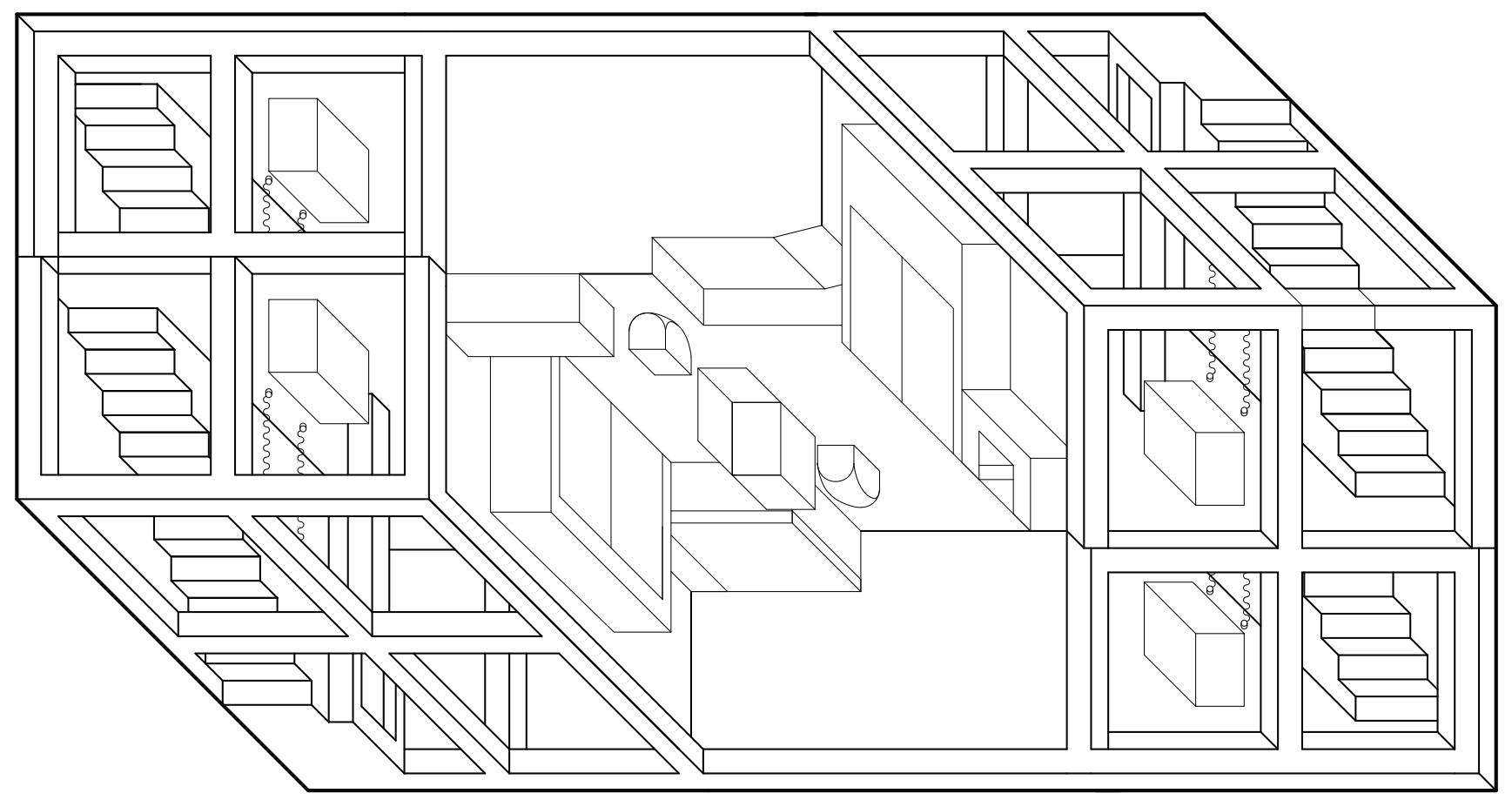

Figure 2. Three Rooms. William Stauffer (extract from Doppelgänger, An Architecture of Estrangement. A graduate design research studio led by Francesco Marullo, UIC School of Architecture, Spring 2018).

the illusion of three-dimensional space on a plane, replacing it by the ultimate illusion of irrational space with attributes of infinite extensibility in depth and forward (...) We live in a field of forces generated by two poles, +-, a society that destroys itself and another one that constructs itself." ${ }^{\prime 6}$

Following Kazimir Malevich's lessons, his master at the Vitebsk Art School in 1920's, Lissitzky retraces the evolution of pictorial techniques and the gradual erosion of linear perspective initiated with the Impressionist discovery of light, later improved by the Cubist fragmentation of objects, the dynamic perception of Futurism and the absolute color composition of Neoplasticism. Suprematism accelerated the trajectory opening up the apex of the visual cone towards infinity and disrupting the perspectival space into a bundle of parallel rays or, in other words, into an axonometric space, as illustrated by Lissitzky's diagrams accompanying the essay Art and Pangeometry: "The reversibility of the conquered parallel projection paved the way towards a purely abstract art derived from a rigorous logical construction, comparable to the discovery of irrational numbers in mathematics:" a whole new mental dimension "that may be entered without an umbrella, where space and time have been combined into a mutually interchangeable single whole." ${ }^{\prime 7}$

Lissitzky tested the axonometric projection through various mediums, from drawings to typographic experiments and book illustrations, from exhibition sets and collages to architectural projects and photographic experiments. In particular, with the series of Prouns (or "Projects for the affirmation of the New") Lissitzky explored the ambiguous territory between painting and architecture. The Prouns were reversible axonometric constructions made of simple arrangements of geometrical forms, in plain colors and lines.

As Yve-Alain Bois noted, the Prouns did dismantle not only the spectator's petrified position towards the painting but also contradicted the very law of gravity, orientation, and compositional balance, transforming the whole process of perception into a mental journey: "We saw that the surface of the Proun ceases to be a picture and turns into a structure around which we must circle, looking at it from all sides, peering down from above, investigating from below. The result is that the one axis of the picture which stood at right angles to the horizontal was destroyed. Circling around it, we screw ourselves into space .... We have set the Proun in motion so we obtain a number of axes of projection." ${ }^{8}$

Indeed, Lissitzky's Prouns operated within a well-established path. Already in 1914, Vladimir Tatlin attempted to break the relation between wall paintings and beholders with his Counter-Reliefs, articulating the flat surface of the image into complex material assemblages that forced the visitors to wander around the work and continuously change their point of observation. ${ }^{9}$ However, the bare materiality of the painting had been violently exposed even before Tatlin by 
Kazimir Malevich's Black Square, that reset the whole art of painting to its zero-degree, representing nothing but itself as a purely physical, optical and emotional fact: canvas, color, density, and form. For Lissitzky, the Black Square embodied precisely the "zero" that liberated art from the constraints of traditional forms, projecting it towards a totally objectless world: a world as pure expression. The Black Square was a new kind of monumentality, no longer expressed by the static and eternal presence of pyramids but by an internal rhythm of life caught in its process of becoming. ${ }^{10}$

In his first Prouns' show at the 1923 Great Berlin Art Exhibition, as in the following ones in Dresden in 1926, and in Hannover in 1927, Lissitkzy brought the Suprematist principles to extreme conclusions. Contesting gravity and orientation, a Proun could not be simply hung on a wall. It had to be distributed along the surface of the room in different positions, challenging the perception of the visitor. Thus, Lissitzky revolutionized the arrangement of the exhibition by subverting and dematerializing the museum organization and transforming the Proun's pictorial depth into real space. He considered paintings not as objects to be contemplated but as elements of a different mental dimension to live in: "New space neither needs nor demands pictures - it is not a picture transposed on a surface. This explains the painter's hostility towards us: we are destroying the wall as a resting-place for traditional painters' pictures."11

Through a specific material treatment of the walls, the alternation of color tones and the balanced disposition of the works on the walls, Lissitzky converted what he called the "zoo experience" of the traditional museum into a dynamic spatiotemporal experience, constructing both physical and abstract space utilizing his paintings. The room was not decorated by Prouns, but it was literally a Proun Space or Prouneraum, as clearly shown by the axonometric layout of the exhibition setup, unfolded in cavalier projection. The project of the gallery was also a Proun: following the same axes but opposite directions, both the floor and the roof flipped upside down, leaving only the doorframe to reestablish a visual orientation. Looking at the drawing, the observer is puzzled and rejected at the same time from the ambivalent order of the image, at once inside and outside, seen from above and within, as the author in Golyadkin's monologue.

In Lissitzky, axonometry did not merely abolish perspective. It produced a reversible image of the world, an image aiming not at involving the beholder but rather at distancing it from the very process of perception. Reversibility generates doubts about what is seen: by posing questions, it demands a choice to be made. ${ }^{12}$ As Golyadkin, the reader/observer vacillates disoriented in the conceptual emptiness left open by the contradictions of its forms. And yet, the visitor could understand space only when removed from the earth, distanced from a stable point of contact, estranged. The gallery was no longer conceived as a simple background for art pieces but as an optical medium for the beholders to reconsider their own position in the world: "traditionally the viewer was lulled into passivity by the paintings on the walls. Our construction/design shall make the man active. This is the function of our room... With each movement of the viewer in space the perception of the wall changes; what was white becomes black, and vice versa. Thus, as a result of human perceptual dynamic is achieved. This play makes the viewer active... The viewer is physically engaged in an interaction with the object on display."13 In other words, for Lissitzky a Proun was not just a mere drawing or a puzzling experimental image, but an instrument of consciousness.

In a moment when a massive discontent towards politics and traditional forms of representation is rewriting the history of Western democracy, Dostoevsky's Double and Lissitzky's Prouns seem, paradoxically, more actual than ever. Annihilating the superiority of a narrator and the observer, destroying the uniqueness of a perspectival construction suggesting multiple points of view, contesting the hierarchical organization and the formal balance of narration through streams of dialogic exchanges and reversible orientations, Dostoevsky's Double generates a technique to plumb the depths of the alienated soul. Similarly, for Lissitzky the foreign distance becomes a project, a method to generate images for understanding rather than seeing, for estranging more than seducing, questioning rather than persuading, analyzing more than representing.

Within and against a system that rapidly transforms everything into a visual episode, wherein communication often counts more than the message itself, consumption more than production, curation more than creation, circulation more than content, Dostoevsky and Lissitzky's estranging distance becomes a way to get a closer and sharper take on reality. Both their reversible, uncanny, axonometric visions could be used as an instrument to analyze the increasing disconnection between living necessities and promised possibilities, between daily struggles and social identities, between the generic labor potential of the human species and its extorted products, between ourselves and our constructed identities or, in other words, what Karl Marx defined as alienation.

Alienation is a separation from ourselves, the laceration of immanent duplicity: on one side, labor power exhausted, bodies exploited, souls indebted and lost in themselves; on the other one, the increasing distant abstractions of social rights, democracy, citizenship, and freedom. If in the 19th century, alienation was the manifested symptom of modern industrialization, today it became a ubiquitous condition, no matter whether within domestic walls or in streets, while working or consuming. Also, if once the typical response to such a chronic detachment from life was a blasé attitude, today resentful, morose and depressed feelings often erupt in anger, frustration and rage, as witnessed by the recent protests and violent movements of dissensus across all sides of the planet. ${ }^{14}$ 


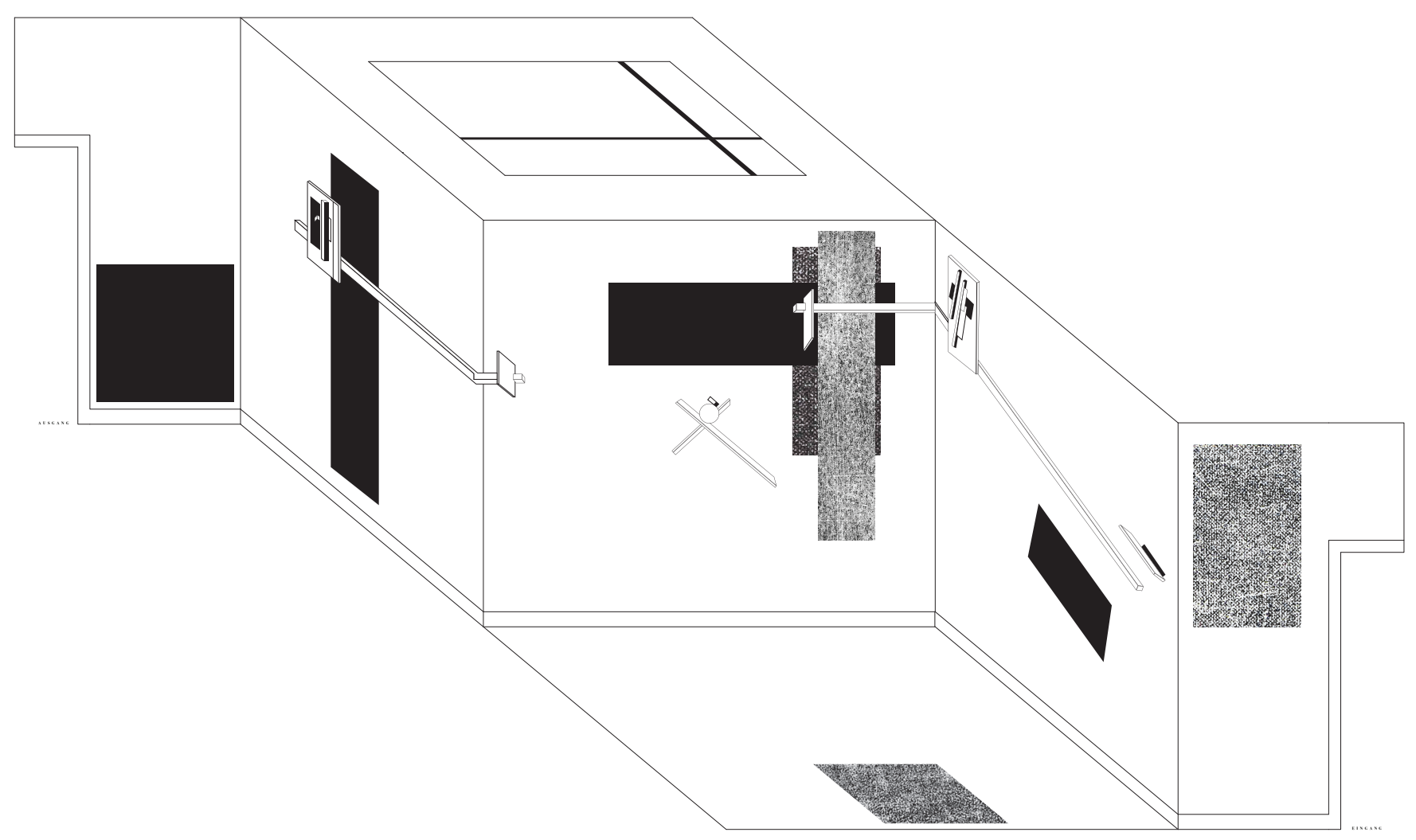

Figure 3. Proun Space, Francesco Marullo, 2019 (redrawn by the author from Plate 6 of the 1st Kestner Portfolio, reproducing El Lissitzky's project for the Prounenraum at the Berlin Art Exhibition, 1923).

However, alienation does not always degenerate into violence and fear. It can also produce self-awareness and recognition of extraneousness to overcome the separation and slavery of a system we have created and continue to feed. Alienation can be reversed into that necessary strain preceding the re-appropriation of our will to action, to reestablish meaningful relations to oneself and the world as "a way of dealing with oneself and the world and of having oneself and the world at one's command." ${ }^{15}$ When endless possibilities for accessing, connecting and sharing information induce a constant desire to exhibit, document and share every single performed activity, the distance of alienation becomes crucial for swerving from the apparatuses managing our lives, away from our curated profiles and codified identities, the ones registered, recorded, stored and updated continuously.

Indeed, the oversaturating waves of images and fake news, the manipulation of communication through social networks, the illicit use of personal information, the supremacy of finance and debt over solidarity and human rights, the leverage of passions and resentment for nurturing divisions and fear, seem an arduous monster to confront with the sole surgical instruments of an estranged perception. Yet, this rudimental form of ascetic detachment should not be considered as a denial of reality or a withdrawal from society but rather an affirmation of existence: a way to look at the conditions in which we live critically, transforming alienation into a possibility for resistance, an antidote against collective hypnosis and social bonds, constructed farces and controlled behaviors. ${ }^{16}$ The axonometric 'gaze' of both Golyadkin's monologues and Lissitzky's Prouns replaces the individual domain of perspective with an un-appropriable and collective instrument, being undefinable within a unique clear vision or a specified observer, indifferent to any top-down or bottom-up approach.

Their abstraction and reversibility turn distance into a space for questioning the limits of individuality and unveiling the common capacities of the human species such as language, thought, self-reflection, and learning. Axonometry defies unified notions of audience, gender, standards or "people" - a category widely exploited by the populist waves haunting countries on both sides of the Atlantic Ocean - fracturing any molar generalization into minor politics, insurgent practices and new subjectivities. ${ }^{17}$ In other words, echoing Robert Venturi's polemic warning from the first pages of his Complexity and Contradiction, the diminished power of architects in shaping the whole environment could perhaps be reversed, ironically, by narrowing their concerns and concentrating on how architecture knowledge is generated more than curating an image of themselves, moving away from problems of representation (of reality, of people, of things) and focusing more on the processes of production, creation, and becoming. ${ }^{18}$ 


\section{ENDNOTES}

1 Manfredo Tafuri, Architecture and Utopia: Design and Capitalist Development, (Cambridge, MA: The MIT Press, 1976), 14.

2 Mikhail Bakhtin, Problems of Dostoevsky's Poetics (Minneapolis: University of Minnesota Press, 1984), 220.

3 Bakhtin, 225-226

4 Massimo Scolari, "Elements for a History of Axonometry," in Oblique Drawing: A History of Anti-Perspective, (Cambridge, MA: The MIT Press, 2012), 1-23.

5 "The paranoiac and the schizoid investments are like two opposite poles of unconscious libidinal investment, one of which subordinates desiring-production to the formation of sovereignty and to the gregarious aggregate that results from it, while the other brings about the inverse subordination, overthrows the established power, and subjects the gregarious aggregate to the molecular multiplicities of the productions of desire. And if it is true that delirium is coextensive with the social field, these two poles are found to coexist in every case of delirium, and fragments of schizoid revolutionary investment are found to coincide with blocks of paranoiac reactionary investment. The oscillation between the two poles is a constituent aspect of the delirium." Gilles Deleuze and Felix Guattari, Anti-Oedipus: Capitalism and Schizophrenia (Minneapolis: University of Minnesota Press, 1983), 375-376.

6 See El Lissitzky, "A. and Pangeometry," in Russia: An Architecture for World Revolution (Cambridge, MA: The MIT Press, 1970), 142-149; also published in Sophie Lissitzky-Küppers, El Lissitzky: Life, Letters, Texts (London: Thames \& Hudson, 1968), 348-54.

7 Lissitzky, “A. and Pangeometry," 148.

8 Yve-Alain Bois, "El Lissitzky Radical Reversibility” Art in America (April 1988): 160-181.

9 Describing Tatlin's work, the literary critic and theorist Viktor Shklovsky defined this tangible "objecthood" (vehsch' fakturnuiu) as the distinguishing feature of art entirely focused on its own medium, on the very materials by which it was made, finally liberated from the obligations of representation or mimesis. See Viktor Shklovsky, "On Faktura and Counter-Reliefs," in Tatlin (New York: Rizzoli, 1988), 341; see also Maria Gough, "Faktura: The Making of Russian Avant-garde," in Res. Anthropology and Aesthetics 36 (Autumn 1999): 32-59.

10 "In 1913 Malevich exhibited a black square painted on a white canvas. Here a form was displayed which was opposed to everything that was understood by "pictures" or "painting" or "art." Its creator wanted to reduce all forms, all paintings to zero. For us, however, this zero was the turning point. When we have a series of numbers coming from infinity ...6, $5,4,3,2,1,0 \ldots$ it comes right down to the 0 , then begins the ascending line $0,1,2,3,4,5,6 \ldots$ These lines are ascending, but already from the other side or the picture." El Lissitzky, "New Russian Art" in Sophie LissitzkyKüppers, El Lissitzky: Life, Letters, Texts, 333-334.

11 On Lissitzky's Proun Room, see Éva Forgács “Definitive Space: The Many Utopias of El Lissitzky's Proun Room" and Maria Gough, "Constructivism Disoriented: El Lissitzky's Dresden and Hannover Demonstrationsraüme," both in Situating El Lissitzky: Vitebsk, Berlin, Moscow, eds., Nancy Perloff and Brian Reed (Los Angeles: Getty Research Institute, 2003), 47-75, 77-125; and Joan Ockman, "The Road Not Taken: Alexander Dorner's The Way Beyond Art," in Autonomy and Ideology: Positioning and Avant-garde in America, ed., Bob Somol (New York: The Monacelli Press, 1997), 80-120.

12 Considering the reversibility of the Proun, Yve-Alain Bois writes "Lissitzky's concern for the virtual expansibility of axonometric vanishing lines into the foreground as well as into depth. The axonometric image is reversible; it tears free of the ground (Malevitch's term), facilitating aerial views. Lissitzky, who excelled in the 'technical' application of axonometry in his architectural drawings, emphasized this reversibility even more by changing the axis of projection from one object to the next. This Imaginary rotation was to achieve the total reversibility of the drawing. Malevitch was the first Western painter, however, who recognized of this complication: axonometric space is atopical and polymorphous - it is 'abstract.'" Yve-Alain Bois, "Metamorphosis of Axonometry," Daidalos 1 (1981): 56-57.

13 This particular fragment of El Lissitzky's retrospective analysis of the "Demonstrationsraüme" is quoted by Benjamin H. D. Buchloh in his "From Faktura to Factography," October 30 (Autumn 1984): 92-93.

14 "At such moments people feel compelled to act" - claims David Harvey thinking about the riots in London, Stockholm, Paris, Istanbul of the last decade - "they want to tear down and destroy the existing order of things. They want a scapegoat to blame. The capitalist class feeds them racial minorities, women, and immigrant as easy targets for blame. That mood was commonplace in many segments of the population around the USA in summer 2016 (...) In this kind of world, we should not be surprised that right-wing populism and bigoted nationalist and racist movements thrive." See David Harvey, "Universal Alienation," TripleC 16, no.2 (2018): 424-439. See also his Seventeen Contradictions and the End of Capitalism, (London: Profile Books, 2014).

15 Rahel Jaeggi, Alienation, (New York: Columbia University Press, 2014), 36.

16 The very etymology of the word "asceticism" - from the Greek verb askein indicates a form of exercising and rationally control the self, for sharpening its capacities and administering its will to power.

17 "A major or established (i.e. imperial) literature follows a vector that goes from content to expression. Since content is presented in a given form of the content, one must find, discover, or see the form of expression that goes with it. That which conceptualizes well expresses itself. But a minor, or revolutionary, literature begins by expressing itself and doesn't conceptualize until afterward ("I do not see the word at all, I invent it") Expression must break forms, encourage ruptures and new sproutings. When a form is broken, one must reconstruct the content that will necessarily be part of a rupture in the order of things. To take over, to anticipate, the material. Art is a mirror, which goes 'fast,' like a watch - sometimes." Deleuze and Guattari, Kafka: Toward a Minor Literature (Minneapolis: University of Minnesota Press, 1986), 28.

18 Robert Venturi, Complexity and Contradiction in Architecture (New York: Museum of Modern Art, 1966), 14

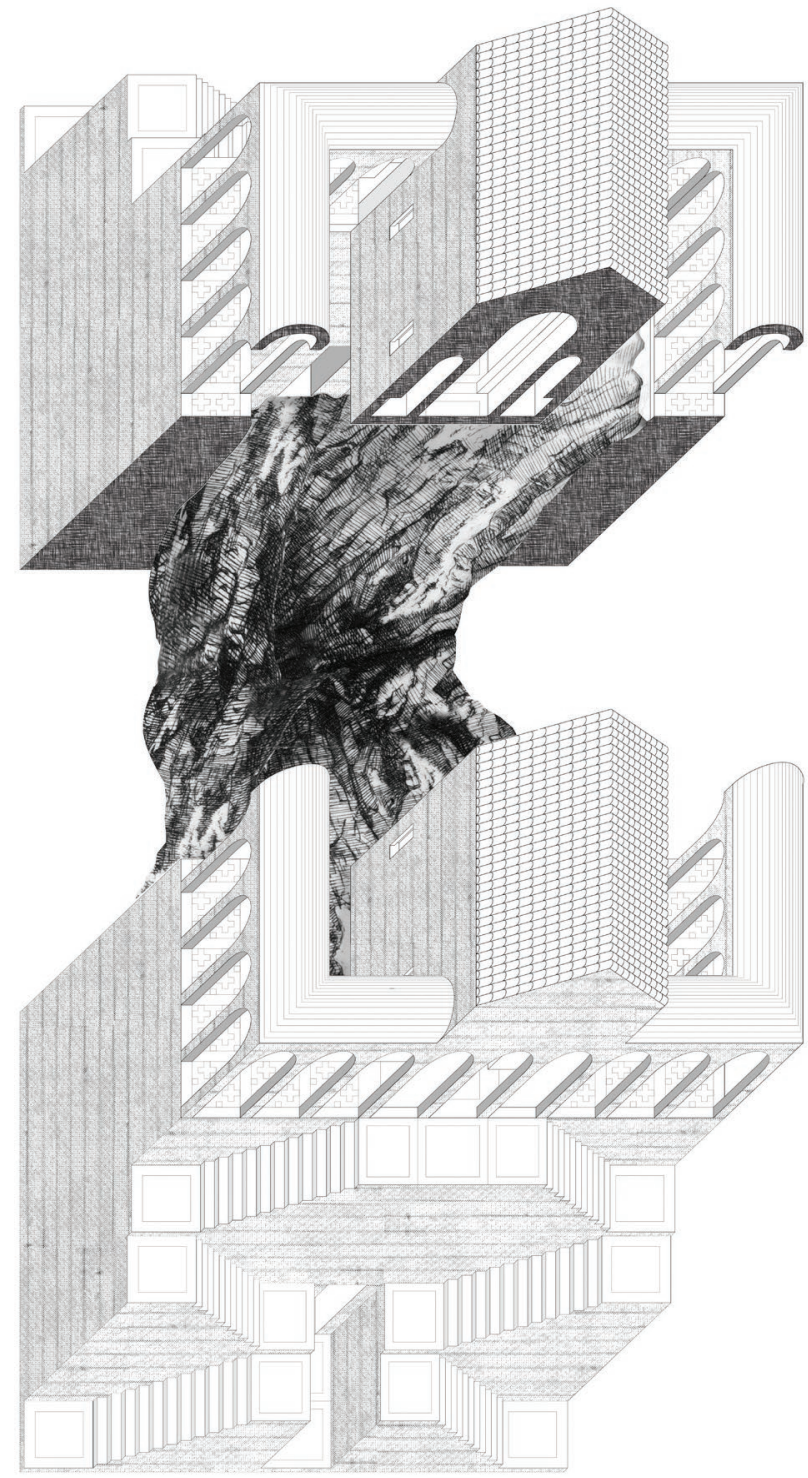

Figure 4. Nine Rooms. Stacie Merz (extract from Doppelgänger, An Architecture of Estrangement. A graduate design research studio led by Francesco Marullo, UIC School of Architecture, Spring 2018). 